\title{
Chromosomal Radiation: a model to explain karyotypic diversity in cryptic species
}

Karine Frehner Kavalco ${ }^{1,4}$, Dinaíza Abadia Rocha-Reis ${ }^{1,4 *}$, Karina de Oliveira Brandão ${ }^{2}$, Jorge Abdala Dergam ${ }^{3}$, Rubens Pasa ${ }^{4,1}$

1. Laboratory of Ecological and Evolutionary Genetics - LaGEEvo, Institute of Biological and Health Sciences, Federal University of Viçosa, Campus Rio Paranaíba, Brazil. +55 (34) 3855-9421

2. Department of Anatomy and Embryology, Leiden University Medical Center, Leiden, Netherlands. +31715269111

3. Laboratory of Molecular Systematic "Beagle", Department of Animal Biology, Federal University of Viçosa - Campus Viçosa, Brazil. +55 (31) 3612-5276

4. Laboratory of Bioinformatics and Genomics, Institute of Biological and Health Sciences, Federal University of Viçosa, Campus Rio Paranaíba, Brazil. +55 (34) 3855-9421

*Corresponding author: dinaizabio@gmail.com

\section{ABSTRACT}

We present a concept that summarizes the pattern of occurrence of widely distributed organisms with large chromosomal diversity, low molecular divergence, and the absence of morphological identity. Our model is based on cytogenetic and molecular data of four populations of the siluriform Hypostomus ancistroides presented in this study in comparison with those of 15 other previously described populations but is applicable to any group of sister species, chronospecies, or cryptic species. Through the evaluation of karyotype macrostructure and physical location of genes, in addition to phylogenetic reconstructions from mitochondrial and nuclear genes, we observed morphologically indistinguishable individuals presenting different locally fixed karyomorphs with phylogeographic discontinuity. The process behind this pattern seen in many groups of cryptic species, in which variation lies mainly in the organization of their genomes but not necessarily in the ecosystems they inhabit or in their external morphology, is similar to the processes behind other events observed in the distribution of lineages. In this work we explain this pattern through the hypothesis of the existence of a process analogous to ecological-evolutionary radiation, the chromosomal radiation, which can be adaptive or non-adaptive, and explore the possibility of applying the concept of chromosomal radiation to different groups of organisms.

Keywords: Adaptive radiation, Chromosomal diversity, Karyotypic polymorphism, Chromosomal speciation. 


\section{INTRODUCTION}

Several models have been proposed to explain the relationship between chromosome evolution and speciation, particularly regarding the mechanisms of fixation of polymorphisms (for a review see Rieseberg 2001; Navarro and Barton 2003; Hoffmann and Rieseberg 2008; Jackson et al. 2016). However, these models have not addressed a practical problem arising from chromosomal speciation: the formation of groups of cryptic species, usually with an intense karyotypic variation. Genomic polymorphisms from hybridisms, as well as events of haploid genome changes, may lead to reorganization of karyotypes, culminating in speciation. In the absence of these events (hybridization and euploidy), the existence of large genomic diversity and karyotype plasticity in the ancestral lineage could explain the emergence of different karyomorphs. These karyomorphs, in turn, can be fixed by evolutionary processes or demographic events, contributing to the formation of new evolutionary units.

Groups with independent evolutionary units with wide geographic distribution usually constitute informative examples of radiation, since adaptive radiation refers to those evolutionary groups that exhibit exceptional extension of adaptive diversification in a variety of ecological niches (Schluter 2000) and non-adaptive radiation can be described as an evolutionary diversification from a common ancestor not accompanied by relevant niche differentiation, but by isolation for competition (Gittenberger 1991). Basic mutation and selection processes alone are sufficient to promote the rapid proliferation of new forms, which supports the theory that compensations in the competitive capacity drive adaptive radiation (Gravilets and Vose 2005). On the contrary, niche conservatism can contribute to the rapid accumulation of lineages by promoting the isolation of derived forms and the multiplication of species through a spatially and temporally floating environment (Kozak et al. 2005).

Plecos of the subfamily Hypostominae (Loricariidae) constitute a large group of fish, megadiverse and with complex taxonomies, organized in approximately 40 genera (Lujan et al. 2015) and 477 valid species (Eschmeyer and Fong 2019). The large variation in characters such as coloration and external morphology (Oyakawa et al. 2005; Zawadzki et al. 2008) and wide distribution in South American rivers means that the genus Hypostomus Lacépède 1803 presents the largest number of species already karyotyped. The group of cryptic species known as Hypostomus ancistroides is one of the bestrepresented species in the literature. 
In the 15 natural populations of $H$. ancistroides already studied, there are 15 different karyomorphs, usually with 2n = 68 chromosomes (Artoni and Bertollo 1996; Alves et al. 2006; Rubert et al. 2011; Alves et al. 2012; Bueno et al. 2012; Endo et al. 2012; Fernandes et al. 2012; Pansonato-Alves et al. 2013; Traldi et al. 2013). However, different diploid numbers (Maurutto et al. 2012) and even the presence of differentiated systems of sex chromosomes of the type XX/XY (Rocha-Reis et al. 2018), and ZZ/ZW (Lara-Kamei et al. 2017) have been observed. Markers, such as C-banding and the location of ribosomal cistrons, present significant variations, although for fish, especially Siluriformes, the available cytogenetic data is quite limited.

Despite these limitations, the classical chromosomal analysis indicates that Hypostomus ancistroides constitute a group of morphologically indistinguishable (cryptic) forms/species, in which allopatric populations are chromosomally differentiated without the presence of clines. In this study, we present molecular and chromosomal data of four new populations of the group and propose a concept based on the idea of radiation of the karyomorphs to explain this population-specific pattern, common in several megadiverse groups of animals and plants.

\section{MATERIAL AND METHODS}

The material analyzed in this study came from four sampling points within the basins of the rivers Tietê, Paranapanema, and Grande, all in the state of São Paulo, Southeastern Brazil. The geographical coordinates of the sampling points are shown in Table 1 and illustrated in Figure 1.

After sampling, living specimens were forwarded to the laboratory, where they were euthanized according to the technical norms of CONCEA (National Council for Control of Animal Experimentation). Subsequently, samples were deposited in the Tissue and Cell Suspension Bank and the specimens were deposited in the Vertebrate Collection of the Laboratory of Ecological and Evolutionary Genetics of the Federal University of Viçosa, Rio Paranaíba Campus (UFV-CRP), Brazil. Taxonomists at the Zoology Museum of the University of São Paulo (MZUSP) identified all lots as being specimens of Hypostomus ancistroides.

Mitotic chromosomes were obtained from samples from the renal tissue of individuals by air drying (Gold et al. 1990). In addition to the conventional Giemsa staining, C-banding was performed to detect constitutive heterochromatin (Sumner 1972) and Fluorescent in situ Hybridization (FISH) (according to Pinkel et al. 1986 and 
Hamkalo and Elgin 1991, adapted by Pazza et al. 2006), using rDNA 5S and 18S probes obtained from PCR (polymerase chain reaction) using H. ancistroides DNA as a template. The primers used in this study are listed in Table 2 . The probes were labeled with biotin14-dATP by Nick Translation using the BioNick Labeling System kit (Invitrogen), following the manufacturer's recommendations. Hybridizations were detected with $\mathrm{Cy} 3$ and the slides mounted with antifade and DAPI (4'-6-diamino-2-phenyl indole). High stringency washes (20\% formamide / $0.1 \mathrm{xSSC}$ ) were performed for 15 minutes and the signal was amplified with biotin-conjugated to anti-avidin, incubated in NFDM-PBS (non-fat dry milk) buffer.

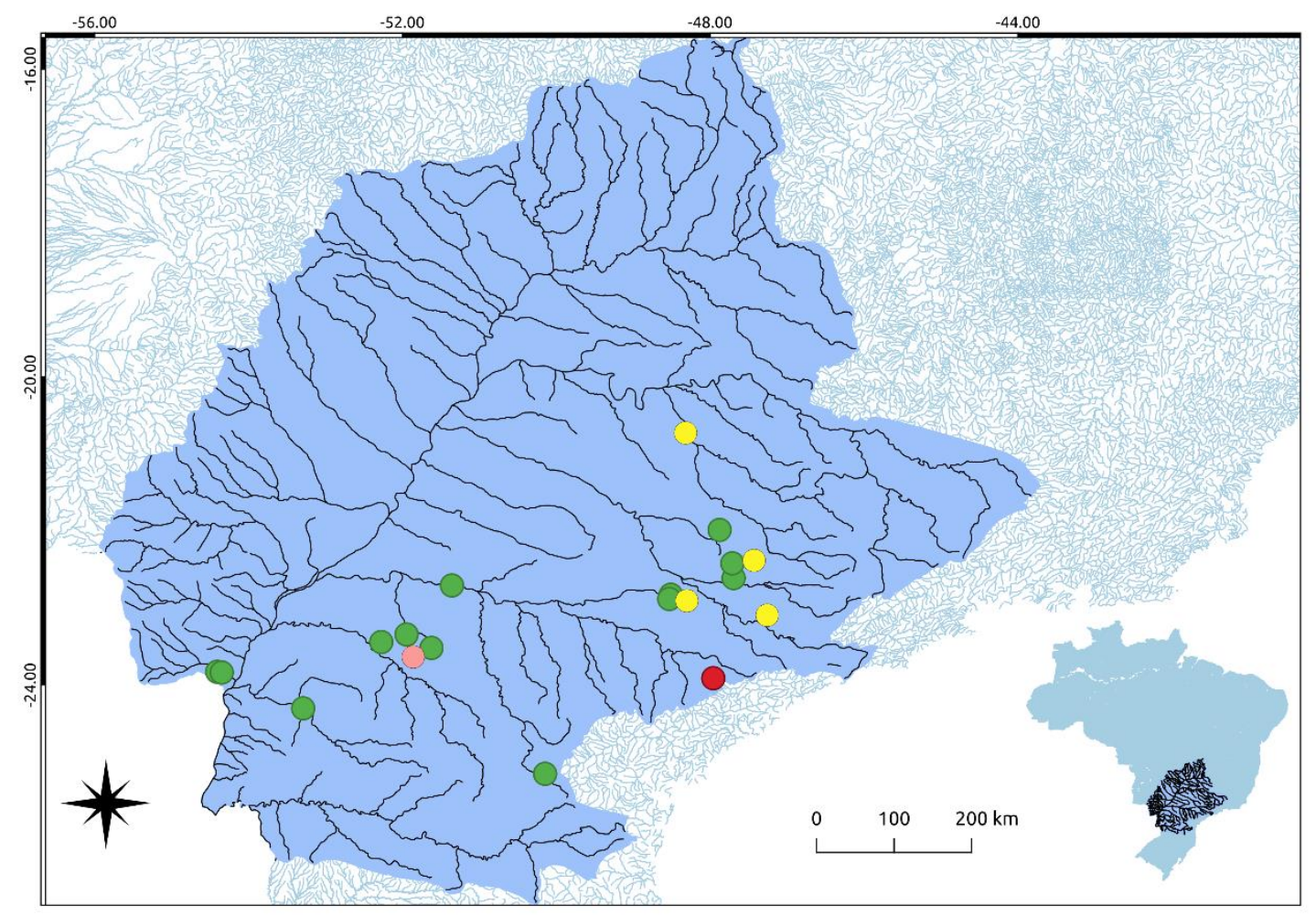

Figure 1: Sampling points along the Tietê, Paranapanema and Grande river basins, highlighting in purple the upper Paraná river system in South America. Data from the literature: in green dots, sampled populations of Hypostomus ancistroides; in red dot, sampled population of Hypostomus aff. ancistroides possessing XX/XY sex chromosomal system; in pink dot, sampled population of Hypostomus aff. ancistroides possessing ZZ/ZW sex chromosomal system; in yellow dots, populations presented in this paper. 
Table 1. Sampling localities and chromosomal data of the Hypostomus ancistroides populations under study.

\begin{tabular}{|c|c|c|c|c|c|c|c|c|c|c|c|}
\hline \multirow{2}{*}{$\begin{array}{l}\text { Population } \\
\text { /City }\end{array}$} & \multirow{2}{*}{$\begin{array}{l}\text { Geographic } \\
\text { coordinates }\end{array}$} & \multirow{2}{*}{$\begin{array}{c}\text { Hydrographic } \\
\text { basin }\end{array}$} & \multicolumn{3}{|c|}{ Specimens sampled } & \multirow{2}{*}{$2 n$} & \multirow{2}{*}{$\mathbf{K F}$} & \multirow{2}{*}{$\mathbf{F N}$} & \multirow{2}{*}{$\mathrm{CB}+$} & \multirow{2}{*}{$18 S+$} & \multirow{2}{*}{$5 S+$} \\
\hline & & & $\mathbf{M}$ & $\mathbf{F}$ & Total & & & & & & \\
\hline Araras & $\begin{array}{l}22^{\circ} 22^{\prime} 59.64^{\prime \prime} \mathrm{S} \\
47^{\circ} 55^{\prime} 46.75^{\prime \prime} \mathrm{W}\end{array}$ & Mogi-Guaçu & 7 & 9 & 16 & 68 & $12 m+12 s m+16 s t+28 a$ & 108 & $2,4,7,16,26,33$ & 13,19 & 6 \\
\hline Botucatu & $\begin{array}{l}22^{\circ} 52^{\prime} 29.15^{\prime \prime} \mathrm{S} \\
48^{\circ} 22^{\prime} 27.50^{\prime \prime} \mathrm{W}\end{array}$ & Tietê & 4 & 5 & 9 & 68 & $12 m+10 s m+16 s t+30 a$ & 106 & $4,7,20,26$ & 12,17 & 31 \\
\hline Indaiatuba & $\begin{array}{l}23^{\circ} 05^{\prime} 39.12^{\prime \prime} \mathrm{S} \\
47^{\circ} 15^{\prime} 38.16^{\prime \prime} \mathrm{W}\end{array}$ & Tietê & 6 & 4 & 10 & 68 & $12 m+10 s m+14 s t+32 a$ & 104 & $1,4,7,10,13,26$ & 14,18 & 3 \\
\hline Terra Roxa & $\begin{array}{l}20^{\circ} 43^{\prime} 34.00^{\prime \prime} \mathrm{S} \\
48^{\circ} 19^{\prime} 15.80^{\prime \prime} \mathrm{W}\end{array}$ & Grande & 2 & 3 & 5 & 68 & $12 m+8 s m+16 s t+32 a$ & 104 & $4,7,21,26,32$ & 11,18 & 27 \\
\hline Total $=\mathrm{N}$ & & & 19 & 21 & 40 & & & & & & \\
\hline
\end{tabular}

M - Males; F-Females; 2n - Diploid Number; KF - Karyotypical Formula (m - metacentric; sm - submetacentric; st - subtelocentric; a - acrocentric chromosome); FN - Fundamental Number; CB+ Chromosome pairs bearing Constitutive Heterochromatin blocks; 18S+ Chromosome pairs bearing $18 \mathrm{~S}$ rDNA sites; $5 \mathrm{~S}+$ Chromosome pairs bearing $5 \mathrm{~S}$ rDNA sites. 
Cytogenetic analysis was accomplished through optical microscopy, and the best metaphases were captured using a camera coupled to an epifluorescence microscope OLYMPUS BX41 with the QCapture Pro 6.0 software. The images were edited to assemble the karyotypes using the software Photoshop 9.0 and GIMP 2.8.14. Chromosomal types were classified taking into account the ratio of the chromosomal arms (Levan et al. 1964).

Mitochondrial (Cytochrome c Oxidase I - mt-co1; Cytochrome b - mt-cyb), and nuclear regions (recombination activation gene 1 - rag1; recombination activation gene 2 - rag2) were sequenced for the phylogenetic analysis. The primers used are listed in Table 2 .

Table 2. Primers used for amplification of ribosomal, mitochondrial and nuclear genes.

\begin{tabular}{|c|c|c|c|c|}
\hline Locus & Primer & Sequence (5', $73^{\prime}$ ') & $\operatorname{Tm}\left({ }^{\circ} \mathbf{C}\right)$ & Reference \\
\hline \multirow{3}{*}{ rDNA 5S } & $5 \mathrm{SA}$ & F - TACGCCCGATCTCGTCCGATC & \multirow{3}{*}{52} & \multirow{3}{*}{ Pendás et al. (1994) } \\
\hline & & & & \\
\hline & $5 \mathrm{SB}$ & R - CAGGCTGGTATGGCCGTAAGC & & \\
\hline rDNA & NS1 & F - GTAGTCATATGCTTGTCTC & \multirow{2}{*}{53} & \multirow{2}{*}{ White et al. (1990) } \\
\hline $18 \mathrm{~S}$ & NS8 & R - TCCGCAGGTTCACCTACGGA & & \\
\hline \multirow{3}{*}{$m t-c o l$} & FishF1 & F - TCAACCAACCACAAAGACATTGGCAC & \multirow{3}{*}{54} & \multirow{3}{*}{ Ward et al. (2005) } \\
\hline & & & & \\
\hline & FishR1 & R - TAGACTTCTGGGTGGCCAAAGA & & \\
\hline \multirow{3}{*}{$m t-c y b$} & CytbFc & F-_GCCCTAATTGATCTCCCCG & \multirow{3}{*}{57} & \multirow{3}{*}{ Lujan et al. (2015) } \\
\hline & $C_{\mathrm{v}}+\mathrm{b} \mathrm{P}$ & $\mathrm{D} \quad \mathrm{CTCCFC \wedge TT \wedge C \wedge \wedge C \wedge CFCCC}$ & & \\
\hline & & 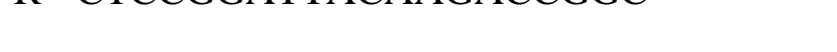 & & \\
\hline \multirow{3}{*}{ ragl } & RAG1Fa & F - CCTGGTTTTCATGCATTTGAGTGGCA & \multirow{3}{*}{53} & \multirow{3}{*}{ Lujan et al. (2015) } \\
\hline & & & & \\
\hline & RAG1R1186 & R - ACGCTCTTCTGARGGAACTA & & \\
\hline \multirow{3}{*}{ rag2 } & $\mathrm{RAG} 2 \mathrm{Fc}$ & F - ATGGAGGCCGAACACCCAACA & \multirow{3}{*}{58} & \multirow{3}{*}{ Lujan et al. (2015) } \\
\hline & & & & \\
\hline & RAG2R961 & R - CGCTGCTGWACTCCATTT & & \\
\hline
\end{tabular}

Tm $\left({ }^{\circ} \mathrm{C}\right)$ - Melting temperature displayed in degrees Celsius

Using the IQ-TREE 1.5.6 software (Nguyen et al. 2015; Chernomor et al. 2016), maximum likelihood phylograms were constructed for each gene sequence obtained. The best nucleotide substitution patterns for each gene were then estimated according to the 
Bayesian Information Criterion (BIC). Analyses were performed with 1,000 bootstrap replicas.

Bayesian analysis of the concatenated sequences was carried out using the software MrBayes 3.2.6 (Ronquist and Huelsenbeck 2003). For each gene, an independent search was made for the best nucleotide substitution model using PartitionFinder 1.1.1 software (Lanfear et al. 2012). After a 50-million-generation run, we evaluated the length of the sampling chain every thousand generations with the Tracer 1.7 software (Rambaut et al. 2018), verifying the effective sample size (ESS) and strand convergence. $25 \%$ of the first trees were discarded as burn-in with the Tree Annotator software v.1.8. All phylogenetic trees were visualized with FigTree 1.4.2 software (Rambaut et al. 2012).

\section{RESULTS}

All specimens analyzed presented a diploid number of $2 n=68$ chromosomes, with different karyotypes in each population, but without supernumerary elements or heteromorphisms related to sex. The results, which demonstrate that each karyomorph presents unique characteristics, but with traces of homology between them, are summarized in Table 1 and illustrated in figures 2 (karyotypes stained with Giemsa and rDNA 18S FISH), 3 (C-banding), 4 (rDNA 5S FISH) and 5 (population idiograms including all markers obtained).

The karyotypes are fairly symmetrical and, although different, have a similar conformation in all populations (Figures 2, 5). In contrast, the 18S rDNA cistrons are always located on subtelocentric chromosomes, in two pairs of very similar size, which probably correspond to homeologous chromosomes between the different populations (Figures 2 - detail, 5).

Similarly, probable homologous pairs with heterochromatic blocks can be observed in the four karyomorphs observed: pairs 4, 7, and 26 (Figures 3, 5). In these pairs, the heterochromatic block may have a different size or be in a different position along the chromosome arm. Other blocks restricted to a given population were also observed, which may constitute population markers. For example, only the population of Indaiatuba has C-bands in the first metacentric pair, whereas only a few individuals of the Terra Roxa population have a large $\mathrm{C}+$ block in one of the chromosomes of the acrocentric pair 21 , thus forming a heteromorphism (Figures 3,5).

Generally, we observed two phenotypes concerning the location of the rDNA 5S cistrons, although they occur in just one chromosome pair in the four populations studied. 
The karyomorphs from Araras and Indaiatuba presented the 5S rDNA sites in an interstitial position in the short arm of metacentric chromosomes. The karyomorphs from Botucatu and Terra Roxa presented them in the terminal position on the long arm of the medium acrocentric chromosomes - chromosome pairs (Figures 4, 5).

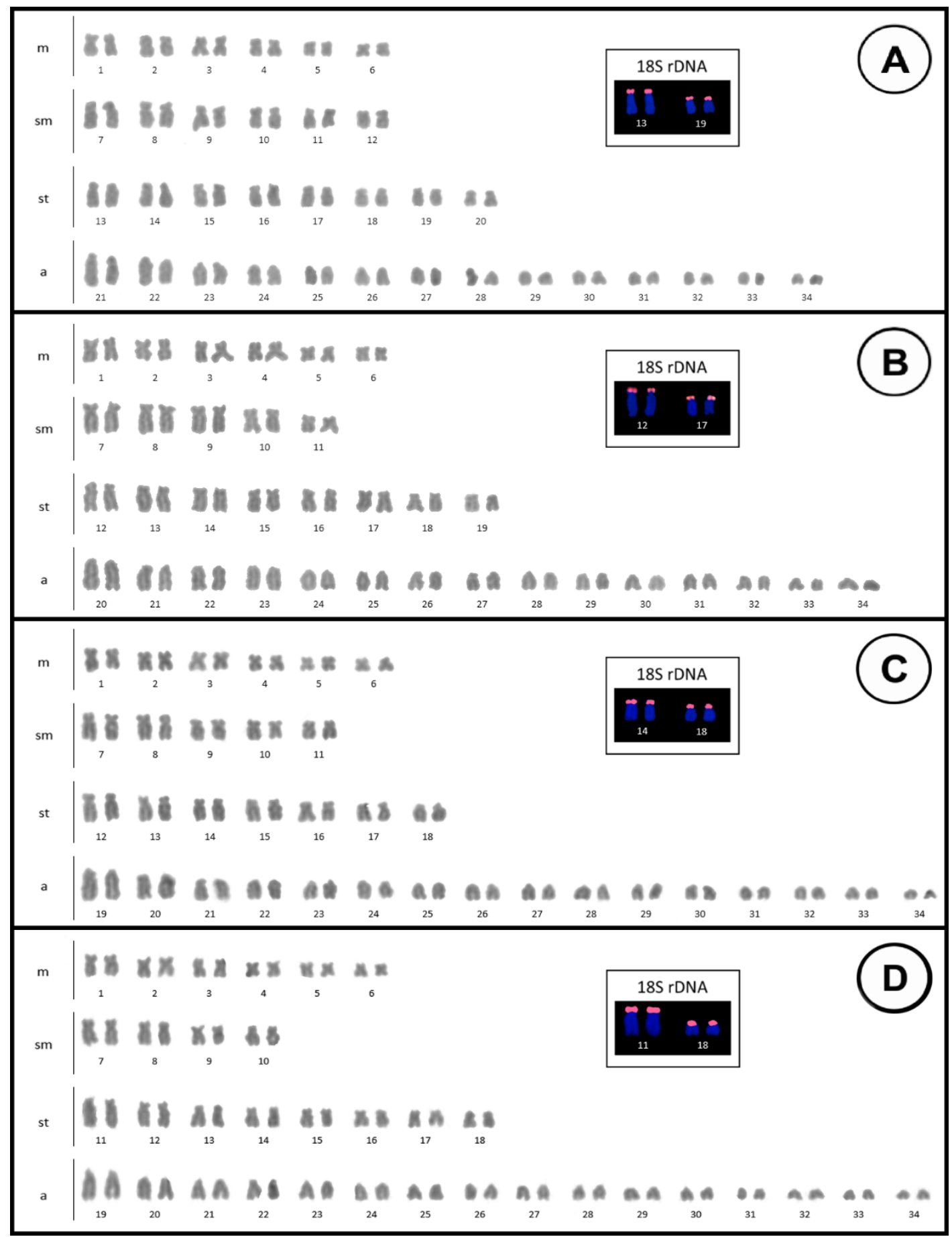

Figure 2: Karyotypes and rDNA 18S gene location (boxes) observed by FISH for the four populations of Hypostomus ancistroides presented in this paper: A - Araras, BBotucatu, C - Indaiatuba, and D - Terra Roxa. 


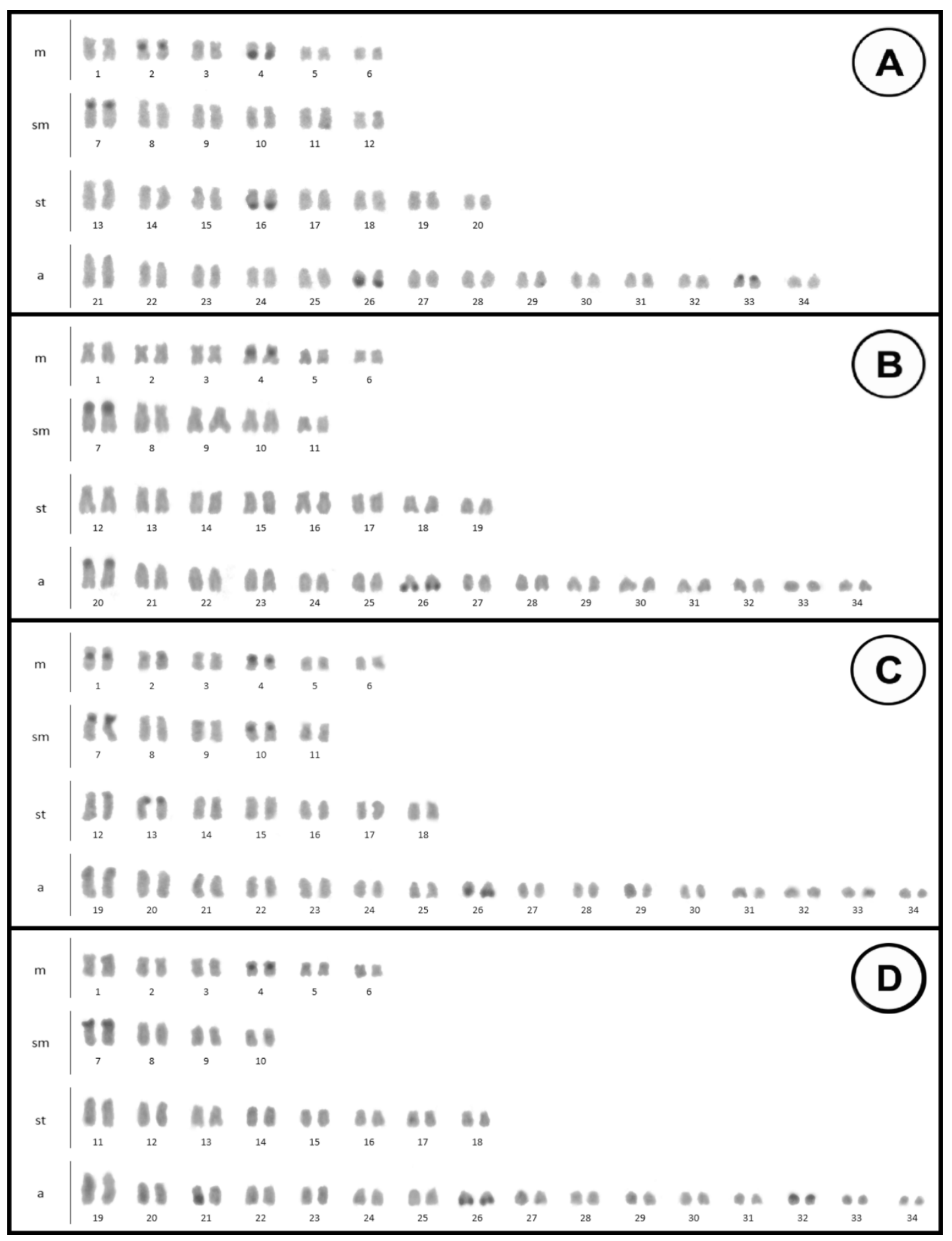

Figure 3: Karyotypes showing the constitutive heterochromatin pattern obtained by Cbanding for the four populations of Hypostomus ancistroides from: A - Araras, BBotucatu, C - Indaiatuba, and D - Terra Roxa. 


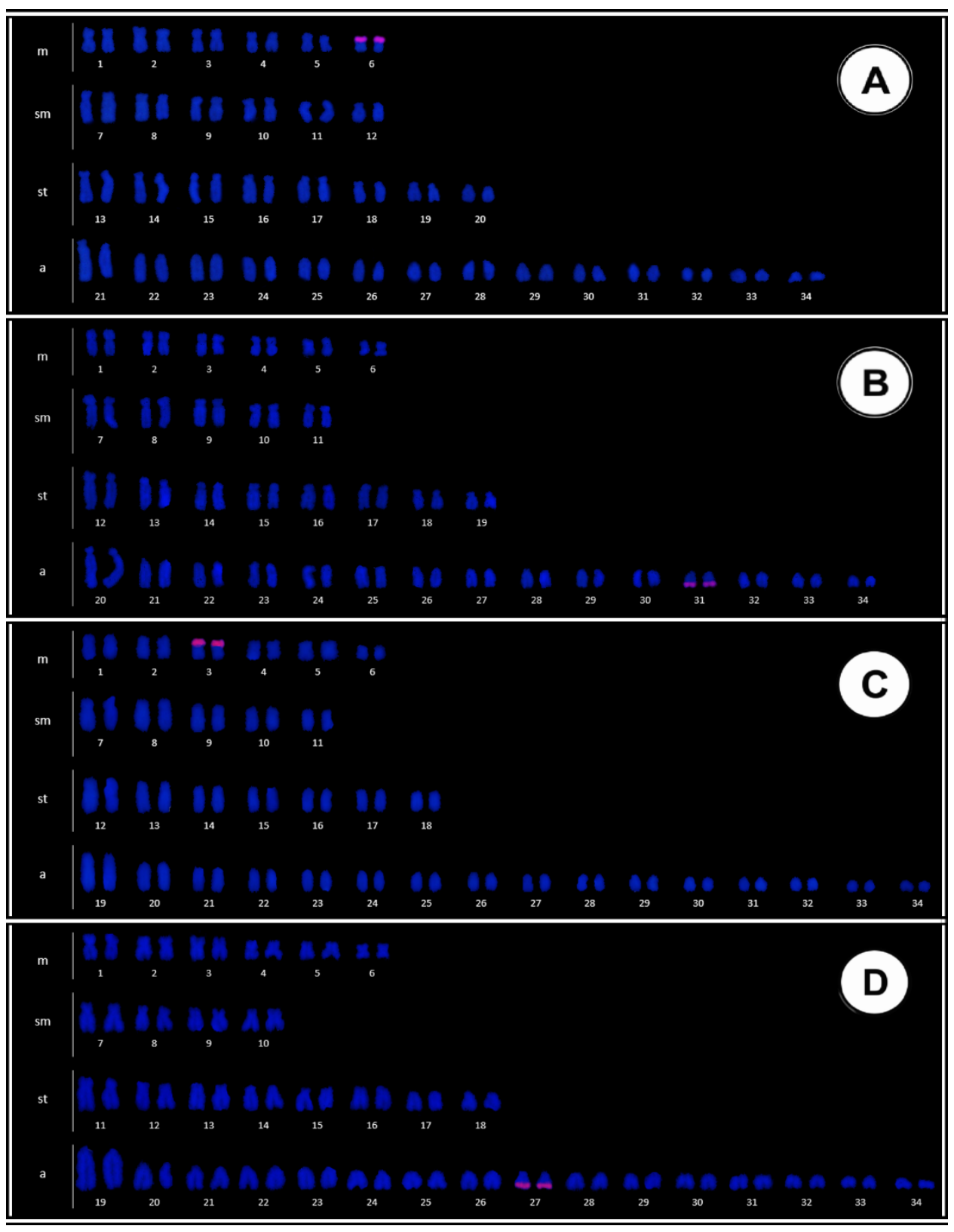

Figure 4: Karyotypes showing the rDNA 5S gene location observed by FISH for the four populations of Hypostomus ancistroides presented in this paper: A - Araras, BBotucatu, C - Indaiatuba, and D - Terra Roxa.

The clusters verified by the configuration of the $5 \mathrm{~S}$ rDNA sites (Figures 4,5 ) are not supported by the molecular data. The tree generated by the Bayesian analysis of the concatenated genes (Figure 6), as well as the other phylogenetic analyses performed, always display two clusters, one formed by individuals from the populations of Araras and Terra Roxa and another by individuals from the Botucatu and Indaiatuba populations. The analyses also show the sharing of haplotypes within each group, but not between the two clusters. The populations of Botucatu and Indaiatuba both live in the Tietê river basin. 
However, Araras and Terra Roxa populations are from several kilometers away and different river basins, without any connection.

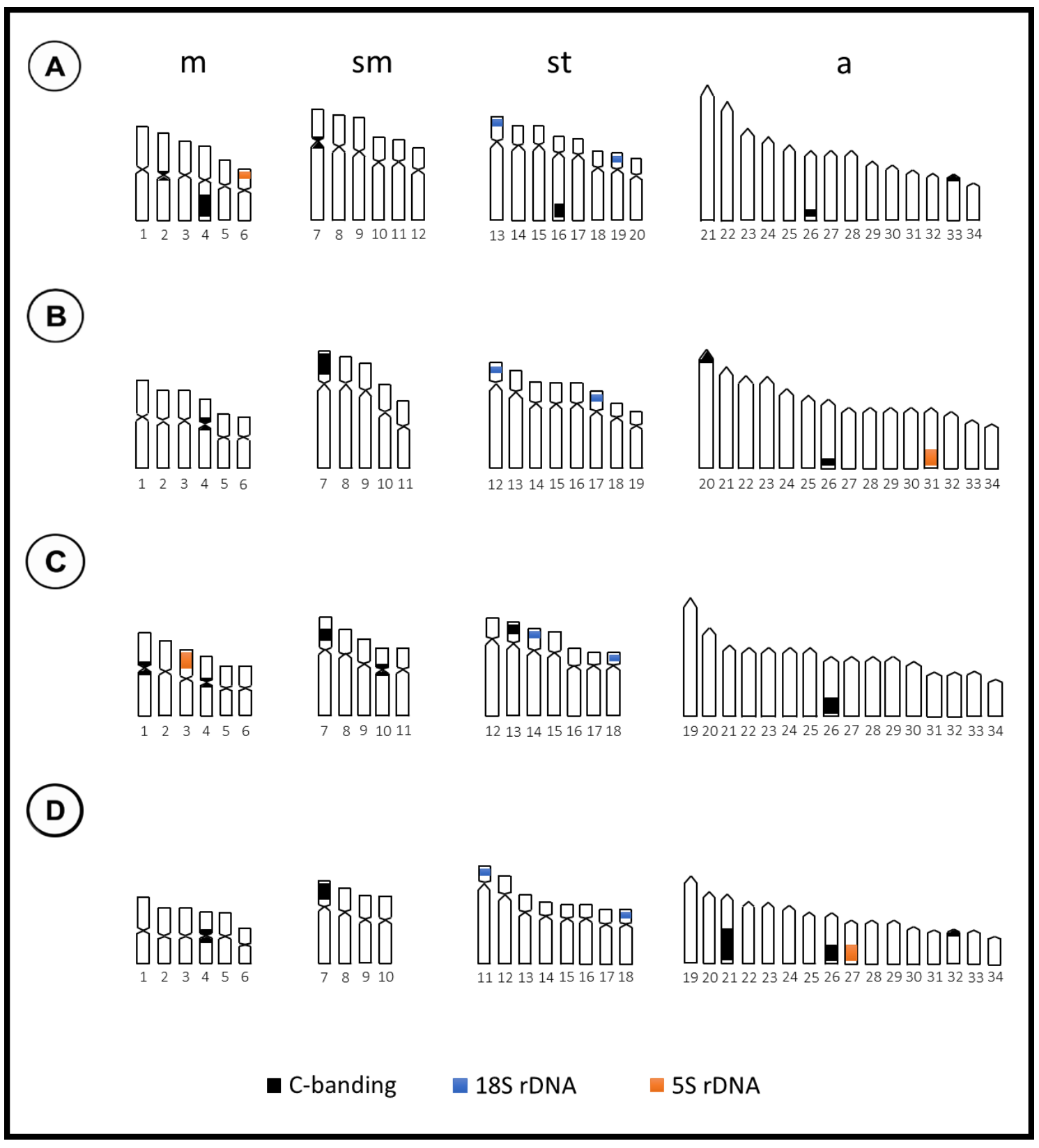

Figure 5: Ideograms summarizing the cytogenetic data observed for the four populations of Hypostomus ancistroides presented in this paper: karyotype constitution with karyotypic formula, C-banding, and rDNA $18 \mathrm{~S}$ and $5 \mathrm{~S}$ location by FISH. A Araras, B- Botucatu, C - Indaiatuba, and D - Terra Roxa.

\section{DISCUSSION}

We herein introduce the concept of "Chromosomal Radiation," which explains not only the karyotype diversity observed in different populations of Hypostomus 
ancistroides but also the diversity patterns observed for many years in the chromosomal studies of various organisms. This concept can be applied to the study of any group of cryptic species, chronospecies, or sister-species, which display low molecular and morphological divergence and large karyotype diversity, i.e., a rapid chromosome evolution.

We believe, therefore, that chromosomal radiation consists of a pattern in which the common ancestor of the group has the potential for karyotype plasticity, enabling the expansion of forms, with new populations presenting different karyotypes, which can be set independently by evolutionary and/or demographic processes. Under this explanation, chromosomal differentiation currently found in populations that do not always show signs of homology would be the result of two main processes: (i) the emergence of rearrangements that generate intrapopulation genetic variability in different lineages, without affecting the reproductive performance of individuals; and (ii) the fixation of different rearrangements independently in different populations over time, leading to the interpopulation variability observed. The pattern observed among populations caused by chromosomal radiation would be similar to that seen in cryptic species of $H$. ancistroides (from the literature and the present study), in which there is a diversity of karyomorphs with markers showing apparently homoplastic phenotypes, without necessarily occurring continuously across geographic distribution and between haplogroups. One explanation for this pattern is that the period of diversification and the time spent during population divergence were so brief that some karyomorphs and haplotypes may have been lost. Such losses prevent one from understanding the entire evolutionary panorama of a group, mainly due to the lack of intermediate forms. Thus, cryptic species complexes where there is a great diversity of karyomorphs with autapomorphies seem to have originated due to plasticity in the ancestral karyotype karyomorph. The multiple karyotypic forms found in cryptic species could constitute, therefore, important examples of non-adaptive or adaptive chromosomal radiation, depending on the relation of the character with the environment.

The role of chromosomal rearrangements in the diversification of species has been a subject of debate for many years, and there is evidence that unbalanced rearrangements can interfere in gametogenesis, reinforcing the reproductive isolation of karyomorphs by reduction of gene flow, as some species have increased tolerance to chromosomal rearrangements, maintaining polymorphic populations or possessing large karyotype plasticity (Pazza et al. 2018). Different models try to explain the fixation of chromosomal 
rearrangements in populations with more or less "adaptation," arguments involving demographic events and evolutionary processes (Rieseberg 2001; Navarro and Barton 2003; Hoffmann and Rieseberg 2008; Jackson et al. 2016). Regardless of the explanations for the appearance and fixation of the existing variation, there is a consensus that chromosomes play an important role in the speciation of several groups of organisms.

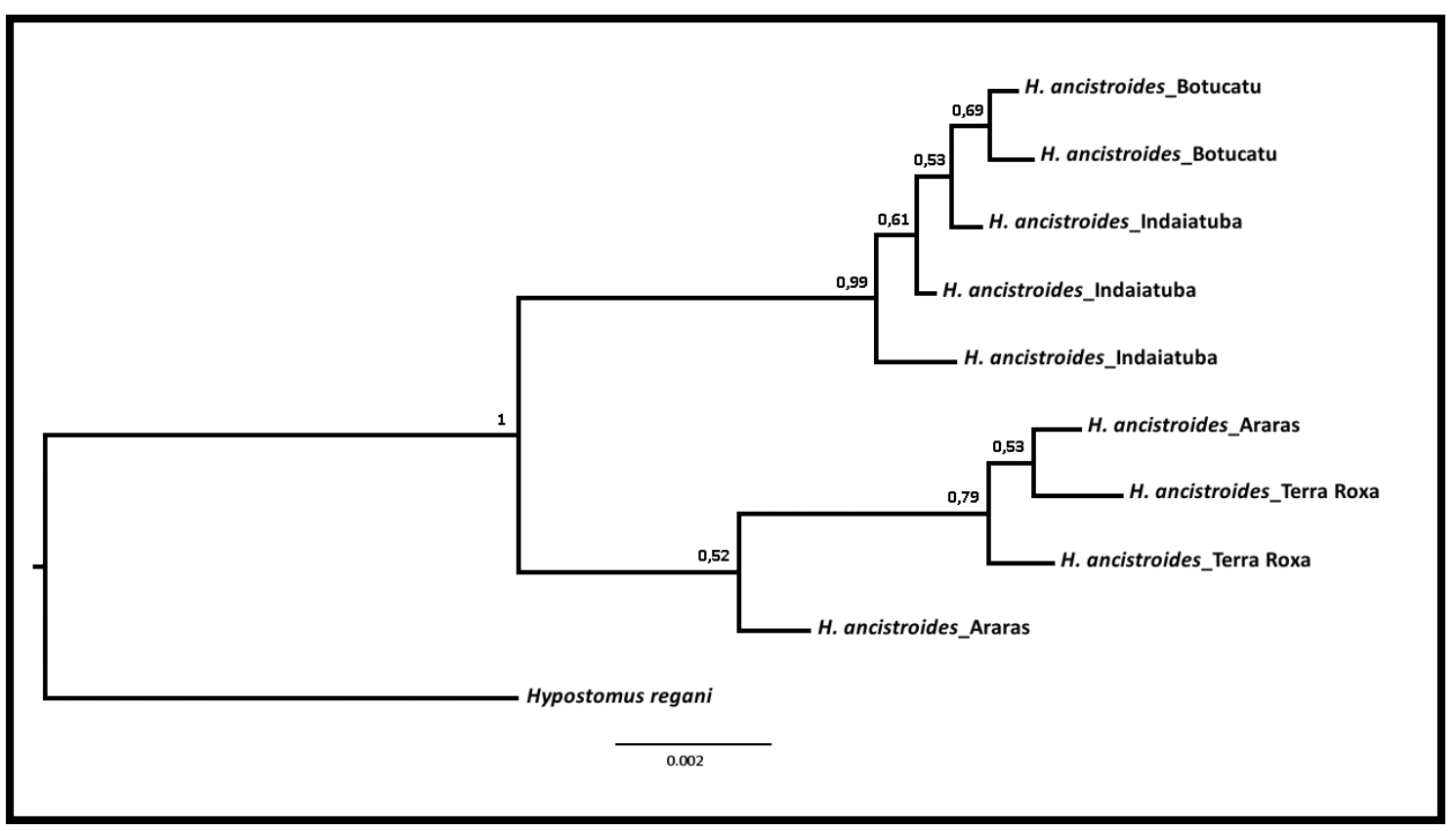

Figure 6: Bayesian tree obtained by concatenation of mitochondrial and nuclear genes sequenced from the four populations of Hypostomus ancistroides. Numbers in nodes represent posterior probability values. Sequences from Hypostomus regani was used as outgroup.

In theory, although frequently a causal factor of differentiation, the accumulation of chromosomal rearrangements can also be the result of evolutionary processes in natural populations. In groups where gene flow persists for a long time between different forms of a lineage, it is very difficult to assign reproductive isolation to chromosomal rearrangements. In species with large karyotype plasticity, for example, equids (Jónsson et al. 2014), the maintenance of gene flow between different karyomorphs appears to be possible, at least for some time. This may occur more often than we estimate, which would explain the discontinuity between molecular and karyotypic evolution seen in some groups with significant chromosomal diversity (Kavalco et al. 2016).

Almost all living organisms possess some karyotype plasticity, although, in certain groups, large plasticity can be considered a characteristic biological trait. This is the case 
in several groups of fish, especially in the tetras of the genus Astyanax (Characiformes) and in the Hypostomus (Siluriformes) plecos, which may have led to the chromosomal radiation present in these groups (for a review see Pazza and Kavalco 2007; Rocha-Reis, et al. 2018). This was also observed in species of Chromaphyosemion (Cyprinodontiformes), especially in C. riggenbachi (Völker et al. 2006). The authors emphasize that karyotypic and haplotypic differentiation suggests speciation in its initial stages and that the karyotype differentiation in $C$. riggenbachi is an ongoing process, in which the rearrangements may be fixed by several processes such as natural selection, genetic drift, or meiotic impulse.

In other vertebrates, such as amphibians, reptiles, and mammals, large diversity associated with specious groups and with wide distribution can also be observed. Rodents are known to constitute a group with a large chromosomal diversity and several polymorphisms. At least seven cryptic species are observed in the African gerbil Taterillus spp., (Dobigny et al. 2001), distinguishable only by their chromosomal characteristics, with karyotypes displaying extensive chromosomal rearrangements (Dobigny et al. 2002a, 2002b). In neotropical Rodentia, extensive Robertsonian chromosome rearrangements, tandem fusions, fissions, and peri and paracentric inversions, besides heterochromatin polymorphisms, have been described. A recent review compiles data on the role of rearrangements in speciation and cytotaxonomy of South American species and demonstrates that the richness of distinct chromosomal forms makes it possible to delimit cryptic species in Akodon, Calomys, Cerradomys, Euryoryzomys, Delomys, Hylaeamys, Juliomys, Neacomys, Oecomys, Oligoryzomys, Ctenomys, Thrichomys, and Trinomys (Di Nizo et al.,2017). It is undeniable that the ancestors of these rodents had the potential for karyotypic plasticity since so many different species arose from the preexisting chromosome variation of natural populations. Thus, we see clear radiation of karyomorphs, most probably due to the pre-zygotic isolation that the chromosomal alterations may have caused.

One group in which there is significant chromosomal diversity and where radiation probably played an important evolutionary role is the genus Drosophila. Dobzhansky had already described polymorphisms in Drosophila chromosomes in the 1930s. In the 1970s more than 80 different karyomorphs were recognized as acting in the diversification of Hawaiian Drosophila spp., having been proposed phylogenies based on chromosomal rearrangements of the group since then. It seems a lot, but it is possible that this number is several-fold higher, since the adaptive radiation that led to the speciation in these 
islands has generated over 700 species and the main chromosomal markers emerged after the 1970s. Similarly, the chromosomal variations described in groups of sister species or cryptic species of many other insects, including beetles, locusts, crickets and mosquitoes (for a historical overview see Dobzhansky 1947; White 1973) are historically extensive.

Chromosomal diversity is not exclusive to animals. In plants, besides hybridisms, numerical and structural polymorphisms and polyploidy events are implicated in the rapid speciation of various groups, with polyploidy considered a paramount adaptive mechanism. In Orchidaceae, one of the most numerous angiosperm families, groups of sister-species and cryptic species feature a large number of karyomorphs, such as Epidendrum (Nóbrega et al. 2017). Similarly, chromosomal diversity in the Asteraceae is substantial and seen in several genera, especially in the patterns of heterochromatin, where differences in the sizes and quantities of $\mathrm{C}+$ bands appear to be related to the presence of rearrangements (see Marinho et al. 2016). In Liliaceae, there is evidence for the occurrence of fusions, fissions, translocations and inversions that generate a great diversity of karyomorphs in several genera, altering karyotypic symmetry (Peruzzi et al. 2009). Karyomorph radiation from an ancestor of high intrinsic diversity, naturally selected or fixed by genetic drift, explains all these patterns.

Several diversifications may contain elements of both adaptive and non-adaptive radiation (Rundell and Price 2009). Similarly, we do not rule out the possibility that there may be an adaptive character in certain chromosomal features of organisms, including $H$. ancistroides, although much of the variation observed appears to be non-adaptive. The maintenance of the diploid number in the plecos in this study, for example, seems to be a group tendency, since the great majority of the studied populations present $2 n=68$ chromosomes (Artoni and Bertollo 1996; Alves et al. 2006; Bueno et al. 2012; Rubert et al. 2011; Endo et al. 2012; Alves et al. 2012; Fernandes et al. 2012; Pansonato-Alves et al. 2013; Traldi et al. 2013; Lara-Kamei et al. 2017) and this could represent an adaptive and ancestral state. The exception for this character is an isolated population in the Tibagi River (Maurutto et al. 2012) and a case of a new species of the H. ancistroides complex carrying a differentiated sexual chromosomal system, which is very divergent from the others (Rocha-Reis et al. 2018).

Another characteristic that seems to be conservative in the group of Hypostomus ancistroides cryptic species and may be adaptive is the presence of at least two subtelocentric or acentric chromosome pairs carrying the 18S rDNA cistrons, a trend observed in several studies (see Rubert et al. 2011; Pansonato-Alves et al. 2013; Traldi et 
al. 2013; Bueno et al. 2014; Lara-Kamei et al. 2017; this study). Thus, it seems quite plausible that we can identify adaptive and non-adaptive traits in karyotypes of groups of sister-species and accept that chromosomal radiation can cover both adaptive and nonadaptive characters, not being mutually exclusive.

Chromosomal variations in Hypostomus are not restricted only to the karyotype formulae, occurring also in patterns of location of the constitutive heterochromatin. Although variable when observing the totality of the karyotype macrostructure, the presence of C-banding in some chromosomes of all karyomorphs may indicate the existence of some homology (Rubert et al. 2011; Fernandes et al. 2012; Maurutto et al. 2012; Pansonato-Alves et al. 2013; Traldi et al. 2013; Lara-Kamei et al. 2017; RochaReis et al. 2018), and may even be considered a phylogenetic sign. In this study, we observed the presence of conserved C+ blocks in pairs of chromosomes $4(\mathrm{~m}), 7(\mathrm{sm})$ and 26 (a), in a pericentromeric or subterminal region (Figures 2 and 4). Other markings, however, were quite autapomorphic. Individuals of $H$. ancistroides from Terra Roxa displayed polymorphisms related to heterochromatin distribution (Figure 2D - pair 21). The absence of blocks in one of the homologs reveals the likely occurrence of unequal exchanges during cell division, where a part or the entire heterochromatin block is translocated to another chromosome. It is interesting that such polymorphisms are observed, especially in heterokariotypes, since the major part of the polymorphisms appears in heterozygosity in populations, and, depending on demographic events and evolutionary processes, can be fixed or eliminated over generations, usually after overcoming subdominance (Hoffmann and Rieseberg 2008; Kirkpatrick 2010) or by selection or genetic drift in small populations (Spirito 1998). This indicates not only that there is variation in the population, but it is in overt process of chromosome evolution.

The dynamics of dispersion of repetitive sequences in chromosomes is often associated with the presence of active transposable elements (TE) in the genomes (SilvaNeto et al. 2015), which could explain the different patterns in the distribution of heterochromatin blocks and rDNAs $5 \mathrm{~S}$ cistrons in different pairs of chromosomes. rDNA sequence analyses have demonstrated the existence of these elements in spacer regions, disseminating gene families in functional copies or pseudogenes (Drouin et al. 1995; Gornung 2013; Rebordinos et al. 2013; Symonová et al. 2013). The dispersion of TEs (and consequently of ribosomal DNA) could then affect the rate of recombination in the genomes and lead to rapid divergence of the karyotype/genome, as observed in the salmonids Coregonus albula and Coregonus fontanae (Symonová et al. 2013). 
The discontinuity between phylogeography constructed from the sequence of four genes (mitDNA and nDNA) and 5S rDNA phenotypes in $H$. ancistroides could be a result of convergence in the location of ribosomal cistrons, generated by translocations in both clusters (Araras + Terra Roxa and Botucatu + Indaiatuba). However, the idea that several derived karyomorphs can be produced from one pluripotent karyomorph as a result of the intrinsic karyotype plasticity of the species is more parsimonious, there being multiple possible forms for each type of chromosome character, and the reality that the chromosomes carrying the sites of rDNA $5 \mathrm{~S}$ are not necessarily homologous to that of the ancestral karyomorph. That is, each new arrangement would be independent in the analyzed forms since they do not appear to be lineages of the same direct ancestor. This would explain not only the distribution pattern of this gene but also the existence of different karyotype formulas and heterochromatic blocks not shared between populations. Chromosomal radiation would, therefore, have generated different karyomorphs in allopatric populations, which may or may not share a haplotype lineage, depending on whether they originated at different times or distributed differently during the genesis of the hydrographic basins

The data presented in this study reinforce the idea that there is a genome-intrinsic karyotype plasticity in some groups. Together with the wide distribution of usually cryptic evolutionary units, chromosomal diversity shows a pattern similar to that of a species radiation, which we conceptualized as chromosomal radiation, which can be both adaptive and non-adaptive.

The recognition of the concept developed in our article may facilitate the discussion of topics related not only to evolution and karyotypic speciation among or within populations, but also to chromosomal evolution itself, including the processes of emergence of variant karyomorphs and specialized chromosomes, such as sex chromosomes, in an eco-evolutionary context.

\section{ACKNOWLEDGEMENTS}

The authors are grateful to experts from MZUSP who identified the specimens analyzed. We also thank CNPq, CAPES, and FAPEMIG for Research, MSc, and PhD scholarships granted to D.A.R.R. and aid granted to the Laboratory of Ecological and Evolutionary Genetics - LaGEEvo. We thank the Graduate Program in Ecology of the UFV - Federal University of Viçosa for support in the publication of this study (grant FORTIS-FAPEMIG). 


\section{CONFLICT OF INTEREST STATEMENT}

All authors declare that they have no conflict of interest. All institutional and national guidelines for the care and use of laboratory animals were followed.

\section{DATA ACCESSIBILITY STATEMENT}

DNA sequences will be deposited in GenBank after acceptance of the manuscript.

\section{REFERENCES}

Alves AL, Oliveira C, Nirchio M, Granado A, Foresti F (2006) Karyotypic relationships among the tribes of Hypostominae (Siluriformes: Loricariidae) with description of XO sex chromosome system in a Neotropical fish species. Genetica 128:19. https://doi.org/10.1007/s10709-005-0715-1

Alves AL, Borba RS, Pozzobon APB, Oliveira C, Nirchio M, Granado A, Foresti F (2012) Localization of $18 \mathrm{~S}$ ribosomal genes in suckermouth armoured catfishes Loricariidae (Teleostei, Siluriformes) with discussion on the Ag-NOR evolution. Comp Cytogen 6:315-321. https://doi.org/10.3897/compcytogen.v6i3.2667

Artoni RF, Bertollo LAC (1996) Cytogenetic studies on Hypostominae (Pisces, Siluriformes, Loricariidae). Considerations on karyotype evolution in the genus Hypostomus. Caryologia 49:81-90. https://doi.org/10.1080/00087114.1996.10797353

Bueno V, Zawadzki CH, Margarido VP (2012) Trends in chromosome evolution in the genus Hypostomus Lacépède, 1803 (Osteichthyes, Loricariidae): a new perspective about the correlation between diploid number and chromosomes types. Rev Fish Biol Fisheries 22:241-250. https://doi.org/10.1007/s11160-011-9215-9

Bueno V, Venere PC, Konerat JT, Zawadzki CH, Vicari MR, Margarido VP (2014) Physical mapping of the 5S and 18S rDNA in ten species of Hypostomus Lacépède 1803 (Siluriformes: Loricariidae): evolutionary tendencies in the genus. Sci World J 2014:943825. http://dx.doi.org/10.1155/2014/943825

Chernomor O, Von Haeseler A, Minh BQ (2016) Terrace aware data structure for phylogenomic inference from supermatrices. Syst Biol 65:997-1008. https://doi.org/10.1093/sysbio/syw037

Di-Nizo CB, Banci KRS, Sato-Kuwabara Y, Silva MJJ (2017) Advances in cytogenetics of Brazilian rodents: cytotaxonomy, chromosome evolution and new
karyotypic
data.
Comp
Cytogen
11:833-892.

https://doi.org/10.3897/CompCytogen.v11i4.19925 
Dobigny G, Moulin S, Cornette R, Gautun JC (2001) Rodents from Adrar des Iforas, Mali. Chromosomal datar $\quad$ Mammalia https://doi.org/10.1515/mamm.2001.65.2.215

Dobigny G, Aniskin V, Volobouev V (2002a) Explosive chromosome evolution and speciation in the gerbil genus Taterillus (Rodentia, Gerbillinae): a case of two new cryptic species. Cytogenet. Genome Res 96:117-124. https://doi.org/10.1159/000063044

Dobigny G, Baylac M, Denys C (2002b) Geometric morphometrics, neural networks and diagnosis of sibling Taterillus species (Rodentia, Gerbillinae). Biol J Linn Soc 77:319-327. https://doi.org/10.1046/j.1095-8312.2002.00074.x

Dobzhansky T (1947) Adaptive changes induced by natural selection in wild populations of Drosophila. Evolution 1:1-16. https://doi.org/10.2307/2405399

Drouin G, de Sá MM (1995) The concerted evolution of 5S ribosomal genes linked to the repeat units of other multigene families. Mol Biol Evol 12:481-493. https://doi.org/10.1093/oxfordjournals.molbev.a040223

Endo KS, Martinez ERM, Zawadzki CH, Paiva LRS, Júlio Júnior HF (2012) Karyotype description of possible new species of the Hypostomus ancistroides complex (Teleostei: Loricariidae) and other Hypostominae. Acta Sci Biol Sci 34:181-189. https://doi.org/10.4025/actascibiolsci.v34i2.9318

Eschmeyer W, Fong JD (2019) Species by Family/Subfamily. Catalog of Fishes: Genera, Species, References. http://researcharchive.calacademy.org/research/ichthyology/catalog/SpeciesByFamily.a sp. Accessed 20 May 2019

Fernandes CA, Damásio JF, Martins-Santos IC (2012) Cytogenetics studies in species of family Loricariidae (Osteichthyes, Siluriformes) from Iguatemi river basin, Brazil. First cytogenetic report in Farlowella amazonum (Günther, 1864). Caryologia 65:276-280. https://doi.org/10.1080/00087114.2012.752913

Gavrilets S, Vose A (2005) Dynamic patterns of adaptive radiation. Proc Natl Acad Sci 102:18040-18045. https://doi.org/10.1073/pnas.0506330102

Gittenberger E (1991) What about non-adaptive radiation? Biol J Linn Soc 43:263272.

Gold JR, Li YC, Shipley NS, Powers PK (1990) Improved methods for working with fish chromosomes with a review of metaphase chromosome banding. J Fish Biol 37:563575. https://doi.org/10.1111/j.1095-8649.1990.tb05889.x 
Gornung E (2013) Twenty years of physical mapping of major ribosomal RNA genes across the teleosts: a review of research. Cytogenet Genome Res 141:90-102. https://doi.org/10.1159/000354832

Hamkalo BA, Elgin SCR (1991) Methods Cell Biology, vol 35. Functional Organization of the Nucleus: a Laboratory Guide. Academic Press, San Diego

Hoffmann AA, Rieseberg LH (2008) Revisiting the impact of inversions in evolution: from population genetic markers to drivers of adaptive shifts and speciation? $\begin{array}{lllll}\text { Annu } & \text { Rev } & \text { Ecol } & \text { Syst } 21-42 .\end{array}$ https://doi.org/10.1146/annurev.ecolsys.39.110707.173532

Jackson B, Butlin R, Navarro A, Faria R (2016) Chromosomal rearrangements and speciation. Enc Evol Biol 4:149-158. https://doi.org/10.1016/s0169-5347(01)02187-5

Jónsson H, Schubert M, Seguin-Orlando A, Ginolhac A, Petersen L, Fumagalli M, Albrechtsen A, Petersen B, Korneliussen TS, Vilstrup JT, Lear T, Myka JL, Lundquist J, Miller DC, Alfarhan AH, Alquraishi SA, Al-Rasheid KAS, Stagegaard J, Strauss G, Bertelsen MF, Sicheritz-Ponten T, Antczak DF, Bailey E, Nielsen R, Willerslev E, Orlando L (2014) Speciation with gene flow in equids despite extensive chromosomal plasticity. Proc Natl Acad Sci 111:18655-18660. https://doi.org/10.1073/pnas.1412627111

Kavalco KF, Pazza R, Brandão KO, Garcia C, Bertollo LAC, Almeida-Toledo LF (2016) Chromosomal diversification higher than molecular variation in Astyanax aff. $\begin{array}{lllll}\text { fasciatus } & \text { (Teleostei, } & \text { Characidae). } & \text { Zebrafish }\end{array}$ https://doi.org/10.1089/zeb.2016.1272

Kirkpatrick M (2010) How and why chromosome inversions evolve. PloS Biol 8:e1000501. https://doi.org/10.1371/journal.pbio.1000501

Kozak KH, Weisrock DW, Larson A (2005) Rapid lineage accumulation in a nonadaptive radiation: phylogenetic analysis of diversification rates in eastern North American woodland salamanders (Plethodontidae: Plethodon). Proc R Soc Lond B Biol Sci 273:539-546. https://doi.org/10.1098/rspb.2005.3326

Lanfear R, Calcott B, Simon YWH, Guindon S (2012) PartitionFinder: combined selection of partitioning schemes and substitution models for phylogenetic analyses. Mol Biol Evol 29:1695-1701. https://doi.org/10.1093/molbev/mss020

Lara Kamei MCS, Baumgärtner L, Paiva S, Zawadzki CH, Martins-Santos IC, Portela-Castro ALB (2017) Chromosomal diversity of three species of Hypostomus Lacépède, 1803 (Siluriformes, Loricariidae), from the Paraná River Basin, Brazil: a 
species complex in Hypostomus ancistroides reinforced by a ZZ/ZW sex chromosome system. Zebrafish 14:357-363. https://doi.org/10.1089/zeb.2017.1429

Levan A, Fredga K, Sandberg AA (1964) Nomenclature for centromeric position on chromosomes. Hereditas 52:201-220. https://doi.org/10.1111/j.16015223.1964.tb01953.x

Lujan NK, Armbruster JW, Lovejoy NR, Lópes-Fernández H (2015) Multilocus molecular phylogeny of the suckermouth armored catfishes (Siluriformes: Loricariidae) with a focus on subfamily Hypostominae. Mol Phylogenet Evol 82:269-288. https://doi.org/10.1016/j.ympev.2014.08.020

Marinho MAO, Sales-Melo MRC, Melo de Oliveira MB, Maciel VEO, de Carvalho R (2016) Karyotype variation in 11 species of the Vernonieae Cass. tribe (Asteraceae Bercht. \& J. Presl). Plant Biosyst 151:291-303. https://doi.org/10.1080/11263504.2016.1174168

Maurutto FAM, Manvailer LFS, Sczepanski TS, Cestari MM, Artoni RF (2012) Cytogenetic characterization of three allopatric species of Hypostomus Lacépède (1803) (Teleostei, $\quad$ Loricariidae). $\quad$ Caryologia 65:340-346. https://doi.org/10.1080/00087114.2012.760882

Navarro A, Barton NH (2003) Chromosomal speciation and molecular-accelerated evolution in rearranged chromosomes. Science 300:321-324. https://doi.org/10.1126/science.1080600

Nguyen LT, Schmidt HA, von Haeseler A, Minh BQ (2015) IQ-TREE: a fast and effective stochastic algorithm for estimating maximum-likelihood phylogenies. Mol Biol Evol 32:268-274. https://doi.org/10.1093/molbev/msu300

Nóbrega SR, Coelho ALF, Verola CF, Costa IR, Vilaça R, Luz FJF, Araújo WF (2017) Chromosome variations and diversity of Epidendrum ibaguense Lindl. (Orchidaceae) on the Tepequém's Tepuy, Roraima, Brazil. Genet Mol Res 16:gmr16039754. http://dx.doi.org/10.4238/gmr16039754

Oyakawa OT, Akama A, Zanata AM (2005) Review of the genus Hypostomus Lacépède, 1803 from rio Ribeira de Iguape basin, with description of a new species (Pisces, Siluriformes, $\quad$ Loricariidae). Zootaxa 921:1-27. http://dx.doi.org/10.11646/zootaxa.921.1.1

Pansonato-Alves JC, Serrano EA, Utsunomia R, Scacchetti PC, Oliveira C, Foresti F (2013) Mapping five repetitive DNA classes in sympatric species of Hypostomus 
(Teleostei: Siluriformes: Loricariidae): analysis of chromosomal variability. Rev Fish Biol Fisheries 23:477-489. https://doi.org/10.1007/s11160-013-9303-0

Pazza R, Kavalco KF, Bertollo LAC (2006) Chromosome polymorphism in Astyanax fasciatus (Teleostei, Characidae). 1. Karyotype analysis, AgNORs and mapping of the $18 \mathrm{~S}$ and $5 \mathrm{~S}$ ribosomal genes in sympatric karyotypes and their possible hybrid forms. Cytogenet Genome Res 112:313-319. https://doi.org/10.1159/000089886

Pazza R, Kavalco KF (2007) Chromosomal evolution in the Neotropical characin Astyanax (Teleostei, Characidae). Nucleus 50:519-543.

Pazza R, Dergam JA, Kavalco KF (2018) Trends in karyotype evolution in Astyanax (Teleostei, Characiformes, Characidae): insights from molecular data. Front Genet 9:131. https://doi.org/10.3389/fgene.2018.00131

Peruzzi L, Leitch IJ, Caparelli KF (2009) Chromosome diversity and evolution in Liliaceae. Ann Bot 103:459-475. https://doi.org/10.1093/aob/mcn230

Pinkel D, Straume T, Gray JW (1986) Cytogenetic analysis using quantitative, highsensitivity, fluorescence hybridization. Proc Natl Acad Sci 83:2934-2938. https://doi.org/10.1073/pnas.83.9.2934

Rambaut A (2012) FigTree, versão 1.4.2. http://tree.bio.ed.ac.uk/software/figtree/

Rambaut A, Drummond A J, Xie D, Baele G, Suchard MA (2018) Posterior summarization in Bayesian phylogenetics using Tracer 1.7. Syst Biol 67:901-904. https://doi.org/10.1093/sysbio/syy032

Rebordinos L, Cross I, Merlo A (2013) High evolutionary dynamism in 5S rDNA of fish: state of the art. Cytogenet Genome Res 141:103-113. https://doi.org/10.1159/000354871

Rieseberg LH (2001) Chromosomal rearrangements and speciation. Trends Ecol Evol 16:351-358. https://doi.org/10.1016/s0169-5347(01)02187-5

Rocha Reis DA, Brandão KO, Almeida-Toledo LF, Pazza R, Kavalco KF (2018) The persevering cytotaxonomy: discovery of a unique $\mathrm{XX} / \mathrm{XY}$ sex chromosome system in catfishes suggests the existence of a new, endemic and rare species. Cytogenet Genome Res 156:45-55. https://doi.org/10.1159/000492959

Ronquist F, Huelsenbeck JP (2013) MRBAYES 3: Bayesian phylogenetic inference under mixed models. Bioinformatics 19:1572-1574. https://doi.org/10.1093/bioinformatics/btg180

Rubert M, da Rosa R, Jerep FC, Bertollo LAC, Giuliano-Caetano L (2011) Cytogenetic characterization of four species of the genus Hypostomus Lacépède, 1803 
(Siluriformes, Loricariidae) with comments on its chromosomal diversity. Comp Cytogen 5:397-410. https://doi.org/10.3897/CompCytogen.v5i5.1589

Rundell RJ, Price TD (2009) Adaptive radiation, nonadaptive radiation, ecological speciation and nonecological speciation. Trends Ecol Evol 24:394-399. https://doi.org/10.1016/j.tree.2009.02.007

Schluter D (2000) The ecology of adaptive radiation. Oxford Series in Ecology and Evolution, 296pp

Silva-Neto LC, Bernardino ACS, Loreto V, Moura RC (2015) Physical mapping of $18 \mathrm{~S}$ and $5 \mathrm{~S}$ rDNA loci and histone $\mathrm{H} 3$ gene in grasshopper species of the subfamily Gomphocerinae (Acrididae). Genet Mol Res 14:15008-15015. https://doi.org/10.4238/2015.November.24.8

Spirito F (1998) The role of chromosomal change in speciation. In: Howard DJ, Berlocher SH (eds) Species and Speciation. Oxford Univ. Press, Oxford, UK, pp 320-329

Sumner AT (1972) A simple technique for demonstrating centromeric heterochromatin. Exp Cell Res 75:304-306. https://doi.org/10.1016/00144827(72)90558-7

Symonová R, Majtánová Z, Sember A, Staaks GBO, Bohlen J, Freyhof J, Rábová M, Ráb P (2013) Genome differentiation in a species pair of coregonine fishes: an extremely rapid speciation driven by stress-activated retrotransposons mediating extensive ribosomal DNA multiplications. BMC Evol Biol 13:42. https://doi.org/10.1186/14712148-13-42

Traldi JB, Blanco DR, Vicari MR, Martinez JF, Lui RL, Barros AV, Artoni RF, Moreira-Filho O (2013) Chromosomal diversity in Hypostomus Siluriformes, Loricariidae) with emphasis on physical mapping of $18 \mathrm{~S}$ and $5 \mathrm{~S}$ rDNA sites. Genet Mol Res 12:463-471. https://doi.org/10.4238/2013.February.8.11

Völker M, Sonnenberg R, Ráb P, Kulmann H (2006) Karyotype differentiation in Chromaphyosemion killifishes (Cyprinodontiformes, Nothobranchiidae). II: Cytogenetic and mitochondrial DNA analyses demonstrate karyotype differentiation and its evolutionary direction in $C$. riggenbachi. Cytogenet Genome Res 115:70-83. https://doi.org/10.1159/000094803

White MJD (1973) Animal Cytology and Evolution. $3^{\mathrm{a}}$ ed. Cambridge University Press. 
Zawadzki CH, Renesto E, Mateus RP (2008) Allozyme analysis of Hypostomus (Teleostei: Loricariidae) from the Rio Corumbá, Upper Rio Paraná basin, Brazil. Biochem Genet 46:755-769. https://doi.org/10.1007/s10528-008-9191-5 